\title{
A dialética das máscaras: o jogo de ocultação e revelação no trabalho do ator
}

The dialectics of masks: the game of concealment and revelation in the work of the actor

José Benedito Almeida Júnior ${ }^{1}$

RESUMO

Este artigo tem por objetivo discorrer sobre os artefatos máscaras utilizados em rituais religiosos e na arte, sob a perspectiva da dialética da revelação e ocultação. Esse fenômeno da dialética apresenta diferentes características ontológicas e psicológicas, pois os rituais de máscaras nas religiões possuem profundos significados e efeitos sobre os indivíduos e sobre a comunidade, sendo superficiais nos outros casos. Apresentaremos, por fim, com base nesta distinção, uma breve análise do papel das máscaras na Commedia dell'arte e o trabalho do ator.

Palavras-chave: Máscaras. Rituais. Commedia dell'arte.

\section{ABSTRACT}

This article aims to debate the masks artifacts used in religious rituals and art, from the perspective of dialectics of revelation and concealment. This dialectical phenomenon presents different ontological and psychological characteristics, since the rituals of masks in religions have deep meanings and effects on individuals and on the community, being superficial in other cases. Finally, based on this distinction, we shall present a brief analysis of the role of masks in Commedia dell'arte and the actor's work.

Keywords: Masks. Rituals. Commedia dell'arte.
1.

Professor do Programa de Pós-Graduação e do Instituto de Filosofia da Universidade Federal de Uberlândia. ORCID: http://orcid.org/ 0000-0001-5801-7284. E-mail:

jbeneditoalmeida@gmail.com 
O uso original de máscaras está associado aos rituais religiosos. Seu uso, no entanto, expandiu-se para outros fenômenos sociais, como as máscaras das festas populares, as máscaras de encenações teatrais, as máscaras como brinquedos e as máscaras dos heróis. Em todos esses casos há um fenômeno que chamamos de dialética das máscaras: o jogo de ocultação e revelação. Nesse artigo nos concentraremos nos três primeiros casos.

As máscaras se caracterizam, por um lado, pela revelação de entidades literárias, folclóricas e outras semelhantes; e no caso das religiões, pela revelação de seres. Por outro lado, caracterizam-se também pela ocultação da pessoa que usa a máscara. Assim, enquanto vela a pessoa, desvela as entidades ou os seres divinos. De todo modo, a dialética se estabelece porque um não existe sem o outro; nesses casos do uso de máscaras, os seres literários ou divinos só se manifestam por meio das máscaras e por intermédio de um ator para a literatura ou folclore, e de um xamã ou feiticeiro, no caso da religião. Essa semelhança faz com que pareça o mesmo fenômeno, mas, como veremos ao longo desse trabalho, a experiência religiosa da dialética das máscaras é muito particular, por suas implicações psicológicas e sociais. Enquanto o primeiro caso nos remete a uma dissimulação ou representação, pois o ator não deixa de ser quem é, apenas representa uma entidade, no segundo caso a pessoa dá lugar aos seres divinos, não como uma encenação ou representação, mas como presença desse ser.

A questão fundamental nesta parte do trabalho é que as máscaras rituais são artefatos simbólicos, isto é, ultrapassam o campo da alegoria ou da representação. Baseamos nossa definição de símbolos no pensamento de Jung: os símbolos são mais profundos do que os signos ou os sinais, pois estes indicam exatamente aquilo que descrevem, enquanto os símbolos indicavam elementos diferentes do que parecem apresentar:

Um conceito ou uma figura são simbólicos quando significam mais do que indicam ou expressam. [...] Como existem muitas coisas que estão além da compreensão humana frequentes vezes - consciente ou inconscientemente - conceitos e figuras simbólicas quando a elas nos referimos [...], não só usamos símbolos, mas também os produzimos espontaneamente em nossos sonhos. O simbolismo é um dado psicológico que merece um aprofundamento maior (JUNG, 2008, p. 202).

A linguagem dos mitos e dos sonhos é, por excelência uma linguagem simbólica: não podem ser lidos ao pé da letra, mas cabe interpretá-los de modo correto. Ora, como os rituais são a vivificação do que os mitos narram, todos os elementos pre- 
sentes num ritual são, portanto, simbólicos - estão além do que parecem, à primeira vista indicar.

Do ponto de vista fenomenológico, podemos dizer que as máscaras são simbólicas, isto é, sua forma, seus desenhos, pinturas e mesmo sua textura não nos remetem ao que é aparente, mas vão além disso. Tal concepção de símbolo é derivada da obra de Carl Gustav Jung:

\begin{abstract}
Assim, uma palavra ou uma imagem é simbólica quando implica alguma coisa além do seu significado manifesto e imediato. Esta palavra ou esta imagem tem um aspecto "inconsciente" mais amplo, que nunca é precisamente definido ou de todo explicado. Quando a mente explora um símbolo, é conduzida a idéias que estão fora do alcance da nossa razão (JUNG, 1992, p. 20).
\end{abstract}

Tendo em vista a distinção entre máscaras sagradas e máscaras profanas ou artísticas, faremos um breve quadro dessas duas categorias distintas.

\title{
As máscaras sagradas
}

A primeira questão com a qual nos deparamos é a definição de máscara. Por vezes, supõe-se que os artefatos máscaras são objetos colocados na cabeça para encobrir o rosto da pessoa, tal como observamos no dicionário Houaiss, verbete máscara: "artefato de papelão, pano, madeira, couro, etc. com que se cobre o rosto para disfarce [...]" (2011). Tal imaginário de máscaras pode ser observado nas representações imagéticas do teatro grego, no qual a máscara era dessa forma utilizada e, também, da experiência das máscaras em festas populares, que trazem essa mesma imagem de um objeto que cobre apenas o rosto do folião. Porém, há outras concepções de máscaras que implicam num plano maior do que esse. Citamos, por exemplo, as máscaras dos rituais Kápa, Iakuigâde e Apapaatai que cobrem o corpo todo do sacerdote, conforme vemos nas obras Os filhos do Sol: histórica e cosmologia de um povo Karib: os Kurâ-Bakairi (2003) e Apapaatai: rituais de máscaras no Alto Xingu. (2008). Assim, ela é composta por uma longa saia, um corpo e mangas que cobrem todo o rosto do xamã. Além disso, há a "cara" da máscara, que define mais precisamente qual entidade será ali recebida. Outra máscara semelhante é a de Obaluaiê, da mitologia Iorubá. Não utilizamos, nesse caso, a palavra representação para esse fenômeno, pois não se trata de uma figuração do ser, mas - do ponto de vista do sagrado - o ser está presente e não representado. 
Quando utilizamos o termo "profana" nos remetemos à obra de Eliade O sagrado e o profano (2010), na qual o autor distingue dois modos de ser no mundo: o do homo religiosus, que não dessacraliza nada no mundo, e do homem europeu ocidental que dessacraliza radicalmente o cosmos. Então, concebe a distinção entre o sagrado e o profano: "O leitor não tardará a dar-se conta de que o sagrado e o profano constituem duas modalidades de ser no Mundo, duas situações existenciais assumidas pelo homem ao longo da sua história” (ELIADE, 2010, p. 20).

No caso das máscaras profanas, podemos dizer que se manifestam em dois grandes grupos: no teatro e nas festas populares. Nesse trabalho, não abordaremos o fenômeno das máscaras no segundo grupo. Interessa-nos, somente, o uso das máscaras no teatro, pois esse também é derivado dos rituais religiosos, porém incorporou elementos das festas populares. Os rituais religiosos parecem estar numa representação; contudo, trata-se de experiências místicas, numinosas, como, por exemplo, o ritual da eucaristia na missa católica: trata-se de um ritual mágico, no qual o ente da pessoa do padre é substituído pelo ser do Cristo; o padre torna-se naquele instante persona Christi, não como um ator, mas como um sacerdote: o ente cede o lugar para o ser. Do mesmo modo ocorre nos rituais apapaatai, kápa, nos rituais do espiritismo, do candomblé durante as possessões.

No caso das máscaras no teatro, pelo menos na experiência ocidental, as máscaras do teatro grego são referenciais. Brandão observa que a máscara prósopon apresenta múltiplas funções ritualísticas, mas, em geral, dois grupos sintetizam esses usos. No primeiro, a máscara é protetora contra forças maléficas; no segundo caso, é o meio pelo qual ocorre a transferência ao portador dos poderes e propriedades dos entes por elas representados. Nesse caso afirma: "O hipókhités em êxtase e entusiasmo é um alter-ego de Dionísio, pois a máscara lhe transferiu todas as propriedades mágicas do deus" (BRANDÃO, 1992, p. 57).

Apesar dessa origem religiosa, o teatro, logo as máscaras também, foram utilizados para encenar situações profanas. Segundo Brandão, Ésquilo foi o primeiro a pintar as máscaras de tal modo que representassem a forma humana, introduzindo, igualmente, cabelos e barbas postiças quando necessário para melhor caracterizar os personagens. Apesar de o teatro tocar os temas religiosos, não são mais feitos no mesmo sentido do numinoso. Brandão observa que houve uma abstração na elaboração das máscaras que levaram o teatro e as máscaras a seguirem uma senda própria: 
A máscara trágica procura traduzir o patético e a dor: rugas profundas, sobrancelhas contraídas, órbitas saltadas, olhos arregalados, boca aberta. Inicialmente individual, a máscara tomou com o tempo um aspecto geral, isto é, passou a representar não um indivíduo, mas um tipo: rei, tirano, rainha, mensageiro... (BRANDÃO, 1992, p. 57).

Os ritos

Há uma infinidade de ritos em todas as culturas, porém, podemos destacar alguns elementos fundamentais que estão presentes nos ritos. Destacamos, então, o tempo, pois há uma periodicidade ou ocasiões em que os ritos são feitos; o espaço, pois os ritos ocorrem em lugares onde houve uma hierofania ou onde se invocou uma; as palavras são geralmente parte integrante dos ritos, tanto pelas ideias que transmitem quanto pela suas enunciações pela voz; os cantos, que incluem, além das palavras, a melodia e o ritmo; os gestos; as danças; a indumentária; os alimentos etc. Enfim, os ritos estão ligados a uma série de elementos fenomênicos cuja variação é infinita, porém sempre ligada ao sagrado.

Sem dúvida há uma grande similaridade fenomênica entre o teatro e os rituais religiosos. Assim, na aparência, pode ser que se assemelhem; contudo, há uma diferença muito grande do ponto de vista ontológico entre um e outro fenômeno cultural.

\begin{tabular}{|l|l|}
\hline \multicolumn{1}{|c|}{ RITUAL } & \multicolumn{1}{c|}{ TEATRO } \\
\hline Mito: as histórias & Texto dramatúrgico: as histórias \\
\hline Rito: a vivificação das histórias & $\begin{array}{l}\text { Peça: a representação das } \\
\text { histórias }\end{array}$ \\
\hline Seres sobrenaturais & Entidades literárias \\
\hline $\begin{array}{l}\text { Sacerdotes, feiticeiros, xamãs e } \\
\text { outros }\end{array}$ & Atores e atrizes \\
\hline Palavras específicas & Palavras do texto \\
\hline $\begin{array}{l}\text { Gestos, cantos, danças, palavras } \\
\text { enunciadas }\end{array}$ & Interpretação \\
\hline Máscaras (quando há) & Máscaras (quando há) \\
\hline
\end{tabular}

Este paralelo nos leva à pensar, num primeiro momento, que pode se tratar da mesma atividade; no entanto, à luz das ciências e da filosofia da religião são atividades ontologicamente muito distintas. A primeira nos remete ao sagrado, ao inteiramente outro, enquanto a segunda é uma atividade 
lúdica que pode ter sentido moral, ético, político e mesmo proporcionar fortes experiências psicológicas para quem assiste e para quem interpreta - no entanto, de natureza completamente distinta da atividade de um ritual religioso. Em síntese, os rituais religiosos são a vivificação do que narram os mitos; as peças de teatro são representações de personagens e situações. Para compreendermos melhor essas diferenças, recorremos a alguns teóricos do fenômeno do sagrado.

Os rituais são compostos de gestos, palavras repetidas tanto escritas como faladas, danças, cantos, paramentos e, claro, em muitos casos, artefatos como as máscaras são as expressões que rompem o espaço e o tempo profanos, permitindo a manifestação do sagrado, isto é, hierofanias. Sob este aspecto, as máscaras apresentam um aspecto dialético: ocultam o sacerdote, o feiticeiro, o xamã para revelar a entidade. Não se trata, pois, de um disfarce, nem de uma "superstição" - como supõe o Homem Moderno - mas da presença do sagrado em meio ao profano.

A compreensão dessa perspectiva passa pela obra de Rudolf Otto, O Sagrado (2011), na qual procurou redefinir essa expressão no seu sentido originário, ligado às religiões e não mais somente à acepção que os filósofos dela fizeram. Para esses, as leis se tornaram sagradas, a razão se tornou sagrada, uma profissão torna-se sagrada etc., o que fez com que o caráter ontológico das experiências religiosas fosse reduzido aos conceitos que a razão pode conceber e enunciar. Otto, então, define como característica do sagrado, em primeiro lugar, o numinoso: este é o poder dos deuses; o transcendente que se manifesta no imanente. Não se trata de um fenômeno que se restringe à razão; ao contrário, a razão não tem condições de definir a profundidade dessa experiência. Não faltam narrativas de experiências místicas pelas quais pessoas de todas as culturas passaram. Enfim, a experiência do sagrado ocorre somente no âmbito das religiões mesmas, conforme Otto:

O elemento de que estamos falando e que tentaremos evocar no leitor está vivo em todas as religiões, constituindo seu mais íntimo cerne, sem o qual nem seriam religião. Presença marcante ele tem nas religiões semitas, e de forma privilegiada na religião bíblica. [...] Para tal eu cunho o termo "o numinoso" [...] referindo-me a uma categoria numinosa de interpretação e valoração bem como a um estado psíquico numinoso que sempre ocorre quando aquela é aplicada, ou seja, onde se julga tratar-se de objeto numinoso." (2011, p. 38).

Assim, as máscaras rituais não têm o mesmo caráter ontológico das máscaras artísticas, pois são artefatos numinosos. Os kurá-bakairi descartam as máscaras depois de utilizadas 
em seus rituais, assim como os wauja do ritual apapaatai. Elas são resultado de hierofanias, isto é, manifestações do sagrado, tanto em sua confecção quanto em seu uso durante os rituais. Por mais que um artista considere seus artefatos e seu saber sagrados, eles estão dentro do campo do profano. Retomamos, então, a concepção de Otto ao afirmar que um artista quando produz máscaras pode estar inspirado, mas nem de longe tal atividade tem o mesmo caráter ontológico que a do artesão quando faz uma máscara ritual; afinal, ele está dentro de uma tradição religiosa a qual deve ser estritamente seguida para que aquele artefato possa ser o lugar de uma hierofania. Desde de sua confecção, até seu uso e posteriormente o descarte, uma máscara ritual deve ser considerada um artefato numinoso muito diferente de uma máscara artística ou artesanal profanas. É como um templo religioso e um prédio qualquer; um alimento sagrado e um alimento qualquer; palavras sagradas e palavras profanas.

No teatro, a encenação toda - bem como o figurino, o cenário e, no nosso caso, especificamente, as máscaras - estão no campo dos signos ou alegorias: representam exatamente aquilo que aparentam. Retomando Jung (1992), não há como uma pessoa produzir um símbolo conscientemente; assim, se o cenógrafo ou mesmo o ator fizerem uma interpretação hermética, colocando determinados elementos que remetem a outra ideia não passará de uma alegoria e não um símbolo. Este se encontra reservado para as atividades do inconsciente, no caso dos sonhos, ou das narrativas míticas.

Nesse sentido, gostaríamos de ponderar algumas interpretações de Caillois sobre o fenômeno das máscaras nos rituais religiosos. Apesar de um extenso e bem realizado trabalho, podemos dizer que Caillois partiu do princípio da antropologia evolucionista; desse modo distingue claramente as sociedades primitivas das civilizadas, reservando o êxtase dos rituais religiosos aos primeiros, conforme vemos na seguinte passagem:

E bastará tudo isso para pretender que a passagem à civilização propriamente dita implica a progressiva eliminação desta conjugação primordial de ilinx e mimicry e a substituição pela proeminência, nas relações sociais, do par agôn-alea, competição e sorte? Seja o que for, causa ou consequência, sempre que uma cultura elaborada consegue emergir do caos original verifica-se uma ligeira regressão das pulsões de vertigem e simulacro (CAILLOIS, 1990, p. 119).

O problema dessa concepção, como ele dirá ao final do parágrafo, é que trata as experiências religiosas de inúmeros povos como "demência e delírio", indicando que há um processo de indiferenciação entre o xamã e a entidade sobrenatural tal como um processo de delírio de uma pessoa da sociedade con- 
temporânea. Destaca, igualmente, que esse processo é obtido por meio de artifícios como o som de tambores, ingestão de narcóticos, esgotamento físico por meio de danças e indumentárias pesadas etc. Assim, o estado místico seria atingido por meio de recursos físicos. Tal visão da religião nas "sociedades primitivas" dificulta compreender o fenômeno do sagrado do ponto de vista de Otto, pois considera que em nossa sociedade não ocorre o mesmo ou, se ocorre, isso se dá como se fosse um delírio, não uma experiência do sagrado.

É nesse sentido que o artigo de Góis (2012), seguindo a senda do pensamento de Caillois, considera que a experiência de um determinado jogo de teatro contemporâneo produz o mesmo efeito da realização de um ritual religioso de máscaras. Em seu artigo, Góis descreve o jogo do "nascimento da máscara" (2012, p. 83) e finaliza a descrição citando o seguinte trecho da obra de Caillois:
É a vitória do fingimento: a simulação atinge um grau de pos- sessão que já não é mais simulada. Depois do delírio e do fre- nesim que ela provoca, o actor readquire a consciência num estado de idiotismo e de esgotamento tais, que apenas lhe resta uma recordação confusa e diluída do que se passou dentro de si, inconscientemente (1990, p. 108).

Ocorre que Caillois insiste em usar termos como "delírio" e "loucura" para descrever os fenômenos do sagrado vividos pelos povos, por ele considerados primitivos. Assim, o homem moderno considera que a experiência do sagrado é a mesma experiência de uma loucura, que, contudo, encerra-se ao final do ritual. Caillois está descrevendo um ritual religioso no qual o sacerdote "[...] alienado, em estado de delírio, acredita que é verdadeiramente o deus cujo aspecto quis assumir, através de um disfarce elaborado ou pueril." (1990, p. 107). Notamos, então, que a expressão "em estado de delírio acredita que é..." indica que o autor não considera que a possessão ou êxtase xamânico é um fato, mas apenas um delírio, algo que não é real. No vídeo Questão do coração, sobre a obra e a vida de Jung, Marie Louise Von Franz inicia dizendo que em seu primeiro contato com o fundador da psicologia analítica, esse lhe contou a história de uma moça que havia ido até a Lua. Ela imaginou que se tratava de uma metáfora ou alegoria, e ele insiste: não, ela foi realmente até a Lua! O homem moderno não consegue compreender a experiência xamânica, pois em sua limitada experiência psíquica, considera que se trata de um simulacro, de uma dissimulação que se tornou um delírio, algo portanto que "não é real".

Outro aspecto da citação acima que merece destaque é que Góis utiliza um trecho da descrição de rituais religiosos em 
comparação com a experiência do teatro. Caillois usa a palavra "actor" para descrever o xamã ou feiticeiro ou ainda o sacerdote que se paramentou e viveu a experiência do sagrado. Por mais que um ator tenha vivido uma experiência psicologicamente profunda em relação a um laboratório conforme o descrito, nem de longe é uma experiência sagrada: está apenas no plano do profano. Nas palavras de Góis:

Se verificarmos uma prática contemporânea de utilização da máscara expressiva, esta também se revela como numa tradição mística. O jogo do nascimento da máscara, no teatro, traz à cena atores epiléticos, contorções vocais, ou seja a vertigem em estado puro (2012, p. 81).

Um paralelo esclarecedor seria o seguinte: um xamã pode ter uma visão, uma experiência mística dentro de sua religião; uma pessoa sob efeito do álcool ou outro tipo de narcótico também pode ter algo parecido com uma experiência mística; no entanto, não passará, este sim, de um delírio. Qual é a diferença, afinal? No primeiro caso, trata-se de uma experiência simbólica, ligada a uma tradição mítica e ritualística em que o sagrado se manifesta. No segundo caso, este sim, é um delírio. Pode ter importância psicológica para o indivíduo, mas não para a sociedade.

Nosso objetivo nessa parte, foi, então, separar radicalmente qualquer atividade profana de atividades do sagrado. Ainda que o paralelismo seja muito interessante e possa ser explorado em diversas áreas do saber, é preciso distinguir o sagrado do profano. Nesse mesmo sentido, de um ponto de vista racional, não podemos julgar as experiências místicas como delírios, como "acreditar que é", e sim como um "o xamã é a entidade". Não se trata de um jogo de faz de conta que chega às raias do delírio, e sim de uma experiência ontologicamente diferente de quaisquer atividades profanas.

Passemos, agora, para a questão das máscaras na Commedia dell'arte, cuja característica, conforme nossas fontes, é a clareza da ideia de que ator e personagem se diferenciam; que se trata, portanto, de uma atividade profissional e não de uma atividade religiosa ou similarmente religiosa.

\section{A Commedia dell'arte ${ }^{2}$}

É no sentido dessa autonomia do teatro como linguagem separada do teatro litúrgico - ainda que aborde temas religiosos ou proporcione experiências psicológicas intensas aos atores e público - que a Commedia dell'arte se destaca. Conforme os artigos que veremos abaixo, os atores da Commedia
2.

A Commedia dell'arte é uma forma de teatro popular que apareceu no século XV na Itália. Suas características são muito particulares, como a presença de certos enredos, personagens, o uso de máscaras, figurinos e uma expressão corporal também peculiares. 
não tinham a pretensão de que seu trabalho fosse similar ao de rituais religiosos: havia uma consciência da profissão de artista. O auto grau de especialização é assim destacado:

Os comediantes trabalhavam durante anos no aprimoramento de sua técnica corporal e vocal, dedicando, geralmente, toda a vida à representação de um único personagem-tipo. Estes personagens eram caracterizados por máscaras, sem expressividade própria, que deixavam a boca e a parte inferior do rosto descobertas, cabendo aos atores a tarefa de conferir-lhes vida por meio de suas performances. Sem as suas virtudes técnicas e sensibilidade artística, vislumbramos apenas um esquema estéril e repetitivo, pois a força da representação delle maschere reside no fato do ator verter criatividade e vigor na especialização de um tipo. Presume-se que, com o passar do tempo, houvesse uma forte apropriação do personagem pelo ator, que poderia ser alçado à categoria de grande intérprete. Além de preservar a tradição dos tipos, a máscara instaurava uma comunicação direta com os espectadores, pois apresentava traços de comportamento mais ou menos fixos, já decodificados e reconhecíveis como tal pelo público (FREITAS, 2008, p. 67).

O artigo de Góis traz uma importante análise das imagens de fotos. No primeiro grupo, na página 81 , os atores estão frente a frente para as máscaras; no segundo grupo, páginas 83 e 84, atores e máscaras estão de frente para o observador da foto. Não se trata somente de uma opção estética, mas de uma mensagem bem clara: eu sou o ator e este o personagem! Há, pois, uma clara diferenciação entre ator e personagem:

Na separação dos olhares, percebemos duas figuras independentes uma da outra. Talvez o fato dos atores passarem muitos anos representando os mesmos personagens seja um dos motivos para que, nestas imagens, o pintor ou o ator, procure definir que a máscara não é o ator, procure distinguir o personagem do ator. Parece que começa a haver um movimento para acabar com uma indistinção entre criador e criatura. Entre a vertigem da dissimulação e o simulacro da representação. $O$ ator aparece com o rosto sereno, sábio, endeusado e a máscara aparece em sua efemeridade, frágil e fugidia. Na Commedia dell'Arte, as máscaras deformes fazem par com as belas enamoradas, o jogo de sedução e repulsa está no centro da nova arte. A vertigem de acreditar ser o personagem deve ser esquecida para que o ator não seja confundido e punido pelas atitudes dos seus personagens, entra em cena o simulacro, o fingir ser, por haver a consciência de exercer uma profissão perseguida. Se antes a dissimulação devia ser exaltada na representação clássica das máscaras, ou mesmo nas máscaras dos bufões, com a Commedia dell’Arte a simulação passa a ser a regra do jogo (GÓIS, 2012, p. 84).

Góis observa que a os atores da Commedia destacaram a diferença para o teatro anterior pela forma como se faziam 
retratar com suas máscaras. Como vimos, seus conceitos de simulação e dissimulação são adequados para o campo da representação teatral, mas não das experiências religiosas ritos em que se usam máscaras especialmente - pois estas não são simulações, mas vivências reais do que narram os mitos. No teatro, contudo, essa presença da ideia de que o ator não é o personagem, não pensa e nem se comporta como ele é fundamental para a arte teatral.

Para o público, porém, esta separação não é verdadeira. Há uma tendência de se confundir o ator com o personagem, ainda mais quando o ator se especializou muito na representação de um personagem ou de um tipo de personagem. As fotos analisadas por Góis parecem indicar a necessidade de distinguir, para o público, o ato do personagem; conforme a citação acima ele até destaca que isso deve acontecer para que o ator não seja confundido e punido pelas atitudes do personagem. Nos permitiremos aqui fazer um breve observação de que os atores de novelas brasileiras que encenam personagens, cujo caráter pode ser dito "mau", sofrem perseguições nas ruas, pois o vulgo considera que ator e personagem são uma única pessoa. Isso se deve, sem dúvida, à qualidade excepcional da encenação que leva a dissimulação a um grau extremo de perfeição. No teatro o efeito é exatamente o mesmo.

Também proporemos um paralelo sobre essa questão da dissimulação. Na obra Paradoxo do comediante ${ }^{3}$, Denis Diderot (1973) também defende esta perspectiva da separação entre o ator e o personagem; contudo, tal separação deve ser dissimulada durante a interpretação, de tal modo que o público não a perceba. Conforme a teoria de Diderot o ator apenas imita as emoções dos personagens, não as sente - pois, dessa forma, como conseguiria encenar o mesmo personagens várias vezes? Na experiência real das paixões, quando sentimos repetidamente as mesmas emoções acabamos amortecidos e aos poucos elas nada mais significam. Enfim, os atores imitam os sentimentos e o público os sente:

Sois vós quem levais convosco todas essas impressões. O ator está cansado e vós, triste; é que ele se agitou sem nada sentir, e vós sentistes sem vos agitar. Se fosse de outro modo, a condição do comediante seria a mais desgraçada das condições; mas ele não é o personagem, ele o representa e o representa tão bem que vós o tomais como tal; a ilusão só existe para vós; ele sabe muito quem que ele não o é (DIDEROT, 1973, p. 463).

A máscara no teatro pode ter o efeito de aumentar essa ilusão que toma conta do público, confundindo ator com personagem, contudo os atores mesmos devem estar cientes de que tal ilusão cabe apenas ao público: ele precisa estar consciente
No teatro francês, especialmente no século XVIII, o termo comediante era equivalente ao que chamamos hoje de ator. 
o tempo todo de suas atitudes dissimulando sentimentos, paixões e intenções.

\section{Considerações finais}

Podemos concluir que o uso de máscaras é comum em diversos fenômenos sociais, como os rituais religiosos, encenações teatrais, festas populares e outros, sendo que em cada um desses usos seus significados são diferentes. Contudo, podemos diferenciar dois grupos: o uso de máscaras em rituais religiosos, nos quais a dialética das máscaras se dá no jogo de ocultação da pessoa e revelação do ser, e o uso das máscaras nos outros casos, nos quais a dialética se dá no jogo de ocultação da pessoa e revelação das entidades. Tal diferença entre ser e entidade é proposto tendo em vista o caráter simbólico das máscaras rituais e o caráter alegórico ou metafórico das outras máscaras.

No caso da Commedia dell'arte os atores assumem que sua arte implica numa diferenciação de uma experiência mística dos rituais de máscaras. $O$ ator não está dando lugar a um outro ser, mas a uma entidade literária - com fortes relações com o folclore, sem dúvida - e nisto implica uma mentalidade da especialização da arte. Tal situação é favorável para melhor compreensão do trabalho artístico em si mesmo, bem como a compreensão da profundidade psíquica das experiências místicas religiosas - no caso estudado neste trabalho, os rituais de máscaras, que não podem ser confundidos com a experiência artística ou dos folguedos de festas populares. 


\section{REFERÊNCIAS}

BARCELOS NETO, Aristóteles. Apapaatai: rituais de máscaras no Alto Xingu. São Paulo: Editora da Universidade de São Paulo; Fapesp, 2008.

BARROS, Edir Pina de. Os filhos do Sol: histórica e cosmologia de um povo Karib: os Kurâ-Bakairi. São Paulo: Edusp, 2003.

BRANDÃO, Junito de Souza. Teatro grego - origem e evolução. São Paulo: Ars Poética, 1992.

CAILLOIS, Roger. Os jogos e os homens. Lisboa: Edições Cotovia, 1991.

DIDEROT, D. Paradoxo sobre o comediante. Coleção Os Pensadores. São Paulo: Abril Cultural, 1973.

ELIADE, M. O sagrado e o profano: a essência das religiões. São Paulo: Martins Fontes, 2001.

FREITAS, Nanci. A commedia dell'arte: máscaras, duplicidade e o riso diabólico do arlequim. Textos escolhidos de cultura e arte populares, Rio de Janeiro, v. 5, n. 1, pp. 65-74, 2008.

GÓIs, Marcus Villa. A máscara na commedia dell'arte. Repertório, Salvador, n. 19, pp. 81-90, 2012.

HOUAISS, Antônio. Dicionário Houaiss da Língua Portuguesa. Rio de Janeiro: Objetiva, 2011.

JUNG, C. G. A vida simbólica: escritos diversos. Trad. Araceli Elman, Edgar Orth. Petrópolis: Vozes, 2008.

JUNG. C. G. (org.) O homem e seus símbolos. Trad. Maria L. Pinho. Rio de Janeiro: Nova Fronteira, 1992.

JUNG, C. G. e outros. Questão do coração: a trajetória do fundador da psicologia analítica. Documentário. Versátil. EUA, 1983, 107 min.

OTTO, Rudolf. O Sagrado. Trad. Walter O. Schlupp. São Leopoldo: Sinodal; Petrópolis: Vozes, 2007. 